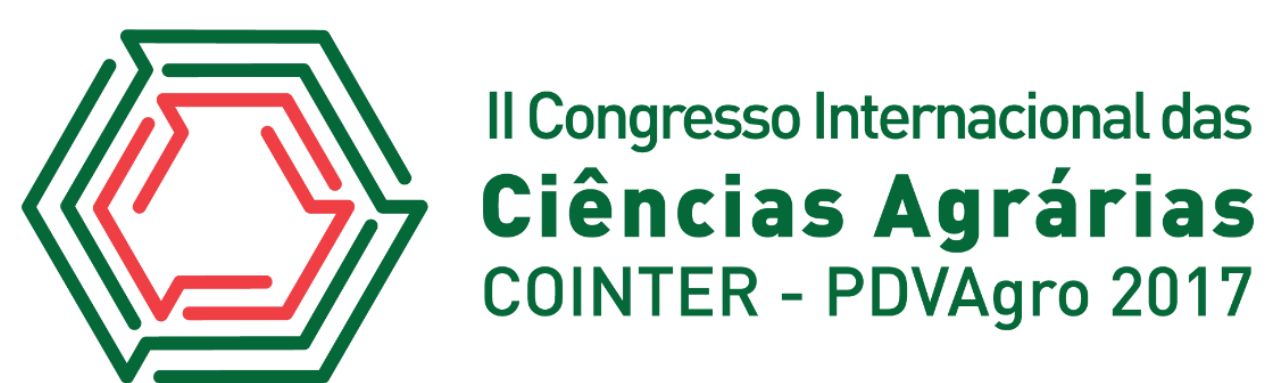

\title{
CARACTERÍSTICAS BIOMÉTRICAS DE SEMENTES CRIOULAS DE FEIJOEIRO COMUM (Phaseolus vulgaris L.) DO MUNICÍPIO DE CANHOTINHO PERNAMBUCO
}

\author{
Apresentação: Pôster
}

\begin{abstract}
Raquel Maria da Silva ${ }^{1}$; Daniela da Silva Andrade ${ }^{2}$; Gleybson Charles Soares dos Santos ${ }^{3}$; Juliete Amanda Theodora de Almeida ${ }^{4}$
\end{abstract}

\section{Introdução}

O feijoeiro comum (Phaseolus vulgaris L.) é base alimentar para diversas nações, no Brasil ele é amplamente cultivado e consumido em todo território sendo importante fonte de nutrientes para a dieta humana. Seu cultivo é realizado no país por muitos produtores com uma diversidade de níveis tecnológicos, sendo que a agricultura familiar é indicada como a responsável pela maior parte do cultivo (SILVA; WANDER, 2013).

As sementes são consideradas insumo base para instalação de um plantio, conforme Matos a diferença entre sementes e grãos é a capacidade de germinar e produzir uma nova planta que a semente possui, sendo assim destinada para o cultivo e o grão é destinado para a alimentação e ainda sim sendo capaz de germinar (MATOS, 2013) e diante disso corrobora que toda semente é um grão mais o inverso não é verídico.

A utilização de sementes oriundas de safras passadas, adquiridas em trocas com vizinhos ou entes queridos é uma prática corriqueira realizada pelos agricultores familiares em diversas localidades da região nordeste do Brasil, assim as sementes crioulas são uma garantia que esse intercâmbio perdure por décadas, ratificando a importância de pesquisa com esta, pois populações de genótipos nativos de Phaseolus vulgaris L. encontram-se sob ameaça constante de extinção pela erosão genética.

Sendo assim as sementes crioulas uma garantia de fonte de variabilidade genética e os

\footnotetext{
${ }^{1}$ Graduanda em Agronomia, UFRPE- Unidade acadêmica de Garanhuns. raquel.maria18@hotmail.com

${ }^{2}$ Graduanda em Agronomia, UFRPE- Unidade acadêmica de Garanhuns. daniela5191@ @otmail.com

${ }^{3}$ Assistente Técnico e Extensionista no Instituto Agronômico de Pernambuco-IPA, lotado no escritório do município de Canhotinho-PE, charlessantos@hotmail.com

${ }^{4}$ Zootecnista, Mestranda na UFRPE- Unidade acadêmica de Garanhuns. Juliete.amanda@ hotmail.com
} 
estudo de características biométricas de sementes é etapa fundamental no conhecimento da variabilidade genética. Então diante do exposto o objetivo do trabalho que foi analisar biometricamente genótipos de feijoeiros crioulos nativos do banco de sementes do Sitio Cabaceiras no município de Canhotinho Pernambuco.

\section{Fundamentação Teórica}

As sementes crioulas se apresentam como uma maneira alternativa de auxiliar os pequenos produtores de uma determinada região ou comunidades para sua sobrevivência, com isso permite produzir seu próprio alimento, possibilitando também sua comercialização, melhorando assim a qualidade de vida dessas pessoas (TRINDADE, 2006). Essas sementes não desempenham somente seu papel na alimentação, mais também se mostra importante na retratação à cultura de um povo expressando também seu modo de vida. Os bancos de sementes crioulas são ferramentas importantes de conservação da diversidade genética de uma região, sendo uma tecnologia de impacto social relevante para a segurança alimentar.

No agreste do estado pernambucano o feijão é cultivado quase em sua totalidade por pequenos produtores, sendo as sementes crioulas utilizadas em maior proporção que as melhoradas geneticamente. O município de Canhotinho localiza-se a uma latitude 0852’38” e a uma longitude 3652’38", apresentando altitude de 520 metros. População estimada em 2017 é de 24.762 habitantes (IBGE, 2015). Possui uma área de 423,168 km² e com clima tropical chuvoso com verão seco e apresenta uma temperatura média anual em torno dos $21,8^{\circ} \mathrm{C}$ (CLIMATE, 2017). A cidade fica à 207,6 km de distancia da capital pernambucana. Na agricultura, os principais produtos são: mandioca, batata-doce, milho, castanha de caju, manga, feijão, banana, melancia.

As sementes crioulas asseguram a conservação dos recursos genéticos existentes e promove à diversidade genética e a exploração destas cultivares pelos programas de melhoramento genético da cultura do feijoeiro (PEREIRA, 2015). Existe uma certa variabilidade de espécies crioulas que são cultivadas por agricultores familiares em pequenas áreas com até 1,0 ha utilizando assim um sistema de baixo recursos tecnológicos (ALMEIDA et al., 2001).

Dentre as várias culturas da agricultura familiar o feijão é considerado uma cultura de importância econômica e social tendo assim sua rusticidade, possibilitando a colheita no período seco (AZEVEDO et al. 2003). Os estudos morfológicos e biométricos de sementes são fatores importantes pois essas características influencia diretamente na identificação, vigor e qualidade da planta, assim como também na sua produtividade. 


\section{Metodologia}

As sementes forma obtidas no banco de sementes crioulas no sítio Cabaceiras na cidade de Canhotinho Pernambuco. Foram realizadas análises biométricas nas amostras de cinco genótipos (Jalo; Ovo de galinha, Caianinha; Preto e Rosinha), realizadas no laboratório de biologia vegetal da Universidade Federal Rural de Pernambuco na Unidade Acadêmica de Garanhuns. As variáveis mensuradas forma: comprimento, largura, espessura e o peso com uma amostra de 100 sementes ao acaso e livres de impurezas. A biometria foi realizada com o subsídio de um paquímetro digital e a sua massa com uma balança analítica modelo AY220. Calculou-se a amplitude, valor mínimo, valor máximo, média, variância e o desvio padrão. As sementes analisadas são da safra de referente ao ano de 2016, eles ficaram acondicionadas em embalagens de polímero termoplástico fechadas hermeticamente em temperatura ambiente.

\section{Resultados e Discussões}

Os dados biométricos de comprimento, largura e espessura são demonstrados na Tabela 1. Verifica-se que para o comprimento a maior amplitude apresentada foi de $8,29 \mathrm{~mm}$ e com uma média de 9,28mm detectado no genótipo Caianinha, os resultados assemelha-se com os de Pereira et al. (2015) que foi de 9,81 mm, em estudo realizado no estado de Pernambuco, o feijão Preto que apresentou uma média de 9,36mm, Borges et al. (2012) encontrou no estado do Acre o valor de 10,54mm. Para a dimensão largura, o genótipo Jalo apresentou uma média de 7,33mm superior aos demais genótipos, Pereira et al. (2015) constatou para o genótipo 7,19mm,tanto o Caianinha como o Rosinha apresentaram 6,02mm. Para a espessura o feijoeiro Rosinha e o Jalo apresentaram 4,65mm e 6,42mm respectivamente, segundo Pereira et al. (2015) foi encontrado para os mesmos genótipos 4,69mm e $5,98 \mathrm{~mm}$

Tabela 1: Estatística descritiva do comprimento, largura e espessura de feijoeiro comum, 2017. Fonte: Própria

\begin{tabular}{|cccccc|}
\hline & JALO & OVO DE GALINHA & CAIANINHA & PRETO & ROSINHA \\
\hline \multicolumn{5}{c|}{ Comprimento dos Grãos } \\
Amplitude & 5,18 & 8,04 & 8,29 & 8,04 & 7,50 \\
Min. & 7,39 & 7,8 & 8,07 & 7,8 & 6.57 \\
Máx. & 10,61 & 11,61 & 10,57 & 11,81 & 10,31 \\
Média & 9,00 & 9,36 & 9,28 & 9,36 & 9.62 \\
Var \pm SD & $0,62 \pm 0,78$ & $0,33 \pm 0,57$ & $0,25 \pm 0,50$ & $0,72 \pm 0,85$ & $0,48 \pm 0,58$ \\
\hline
\end{tabular}




\begin{tabular}{|cccccc|}
\hline \multicolumn{5}{c|}{ Largura dos Grãos } \\
\hline Amplitude & 4,14 & 5,54 & 1,69 & 3,45 & 2,02 \\
Min. & 5,48 & 4,64 & 4,98 & 4,64 & 4,70 \\
Máx. & 8,36 & 7,27 & 6,82 & 7,27 & 6,71 \\
Média & 7,33 & 6,35 & 6,02 & 5,98 & 6,02 \\
Var \pm SD & $0,35 \pm 0,59$ & $0,32 \pm 0,56$ & $0,14 \pm 0,36$ & $0,28 \pm 0,53$ & $0,17 \pm 0,41$ \\
\hline \multicolumn{7}{c}{ Espessura dos Grãos } \\
Amplitude & 5,34 & 2,02 & 2,18 & 2,66 & 4,71 \\
Min. & 4,52 & 4,02 & 3,77 & 4,83 & 3,48 \\
Máx. & 7,79 & 6,03 & 5,86 & 6,26 & 6,55 \\
Média & 6,42 & 5,33 & 4,93 & 5,65 & 4,65 \\
Var \pm SD & $0,28 \pm 0,53$ & $0,19 \pm 0,43$ & $0,16 \pm 0,40$ & $0,14 \pm 0,65$ & $0,26 \pm 0,50$ \\
& \multicolumn{7}{c}{} \\
\hline
\end{tabular}

Quanto ao peso de 100 sementes exposto no Gráfico 1. O feijão Jalo foi o apresentou maior peso com 35,53g, Borges et al. (2012) os valores para Rosinha assemelham-se com os analisados no Acre que foi de 20,33g. Araújo et al.(1996) classificou utilizando esse mesmo método as sementes do seguinte modo : muito pequena $<20$ g; pequena 20 a 30 g; média 30 a 40 g; normal 40 a 50 g e grande $>50 \mathrm{~g}$. Então pelos resultados encontrados as sementes são pequenas, exceto a Jalo que é normal.

Gráfico 1: Peso de 100 sementes de cinco variedades de feijão crioulo, 2017. Fonte: Própria

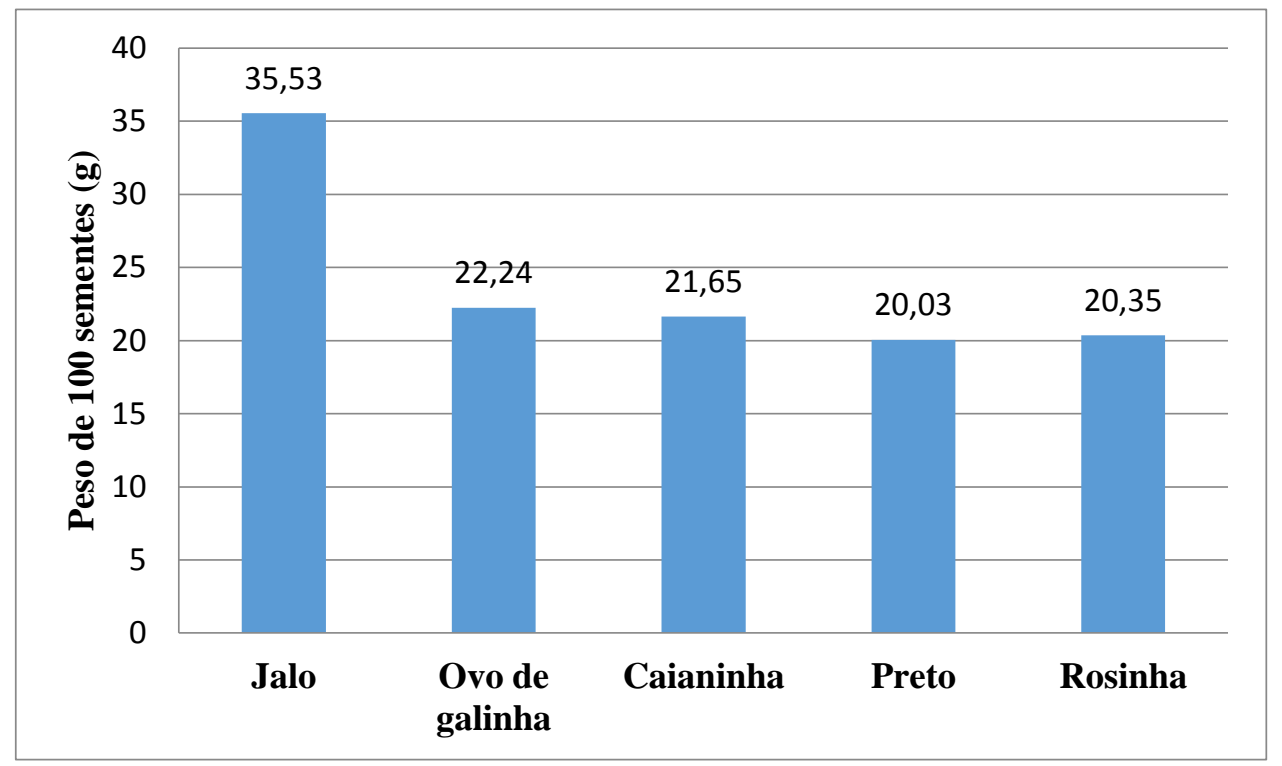




\section{Conclusões}

Levando-se em consideração as características biométricas estudadas nos cinco genótipos de feijoeiro comum, (Phaseolus vulgaris L) pode-se observar que há variabilidade genética.

\section{Referências}

ALMEIDA, P.; CORDEIRO, A. Semente da paixão: estratégia comunitária de conservação de variedades locais no semiárido. Rio de Janeiro: ASPTA, 2002.

BORGES, Vanderley et al. Características biométricas de sementes crioulas de feijoeiro comum do acre. Disponível em:< https://www.embrapa.br/busca-de-publicacoes $>$ Acesso em: 11 de out. 2017

CLIMATE. Clima de Canhotinho. Disponível em:< https://pt.climate-data.org/location/43049/>

IBGE. Diretoria de Pesquisas - DPE - Coordenação de População e Indicadores sociais- COPIS. Disponível em: <https://cidades.ibge.gov.br/xtras/temas.php?lang=\&codmun=260370> Acesso em: 13 de out. 2017.

MATOS, Paulo C. T. Sementes Comestíveis. Disponível em: <http://www.agrolink.com.br/>. Acesso em: 12 out. 2017.

PEREIRA. Rodrigo Gomes. Caracterização de sementes de variedades de feijão crioulo coletadas no município de lajedo-pe. Disponível em:< https://edufersa.ufersa.edu.br/wpcontent/uploads/sites > Acesso em: 13 de out. 2017

SILVA, Osmira F.; WANDER, Alcido E. O Feijão-Comum no Brasil Passado, Presente e Futuro. Santo Antônio de Goiás: Embrapa Arroz e Feijão, 2013.

TRINDADE, Carina Carreira. Sementes crioulas e transgênicos, uma reflexão sobre sua relação com as comunidades tradicionais. Disponível em: < http://www.publicadireito.com.br/conpedi/manaus > Acesso em: 13 de out. 2017 